\title{
I've Got an Idea! Do IDEA Boards Facilitate Improved Completion of Wellness Focused Activities in a College of Nursing?
}

\author{
Jennifer Macali, DNP, MSN, RN, MPH \\ The University of Utah \\ Cheryl Armstrong, DNP, MS, RN \\ The University of Utah
}

\begin{abstract}
Background: In any given academic department there are many ideas discussed to promote wellness, yet it is often difficult to move specific wellness activity ideas from the initial conception stage to the implementation and evaluation stages. Wellness Committees are formed in departments where proposed ideas are generated. However, the same issue of lack of follow-through persists. In order to provide better follow-through and completion of wellness activities, an IDEA board was piloted by a Wellness Committee in a College of Nursing.

Aim: This pilot project was implemented to determine the feasibility and utility of using an IDEA board to implement and complete wellness initiatives within a College of Nursing.

Methods: An online mixed-methods survey was used to evaluate the use of an IDEA board within a Wellness Committee $(n=9)$ in a College of Nursing over a one-year period.

Results: Results of the pilot study were positive and encouraging. Committee members found the visual representation helpful in guiding the group through the process of idea identification generation to idea implementation and evaluation.
\end{abstract}

Conclusions: Using an IDEA board to guide the process of proposed wellness activities may facilitate improved completion of activities.

Submitted 29 January 2021: accepted 9 September 2021

Keywords: wellness, higher education, wellness culture, IDEA board, academic nursing

Promoting wellness among faculty and staff in a health science academic work setting is an important and timely initiative (Amaya et al., 2017). Indeed, one of the Healthy People 2030 goals is "strengthening the workforce by promoting health and well-being" (Office of Disease Prevention and Health Promotion, 2020). Researchers have noted that an individual's lifestyle behaviors directly affect their work productivity, resiliency, and health care costs (Borah, Egginton, \& Shah, 2015; Hill-Mey et al., 2015). Academic work-settings are no exception It is, therefore, paramount for an academic workplace to take measures to promote the health of its workers.

Wellness promotion ideas are often discussed in academic meetings; however, simply verbalizing an idea in a group meeting does not result in implementation of that idea unless a responsible party takes charge. This is where 
the formation of Wellness Committees come into play. These committees have an essential role in creating activities and initiatives focused on promoting health within an organization (Brown et al., 2020). However, even when ideas are discussed in these committee meetings, they often suffer from lack of follow-through. Without well-formulated strategies for implementing ideas and goals, nothing happens. Cheema and Bagchi (2011) noted that as individuals approach a goal or idea, using an external representation that promotes visualization enhances the pursuit and attainment of that goal. One such device is an IDEA board, which is used to guide the process of idea conception, implementation, and evaluation. An IDEA board is a tangible and visible place for ideas to take form, a process that is visibly transparent to all involved in an improvement change (Graban \& Schwartz, 2014). The visual IDEA board process is one type of Kaizen method frequently used in healthcare improvement processes. The word Kaizen in Japanese means "change for the better" (Graban \& Swartz, 2014). IDEA boards are commonly and successfully used as part of process improvement in healthcare settings, especially at the unit or department level. IDEA boards are typically whiteboards or cork boards placed in a visible area in a department or unit. The board offers the opportunity for ideas to move from the idea phase to the completion phase, while making the steps of the process visible for all.

According to Graban and Swartz (2014) there are several steps to an IDEA board, beginning with identifying the idea, then proceeding to identifying specific steps that must be completed to successfully implement the idea. Once the idea is in the implementation stage, notes are made of the steps taken to ensure completion. When completed, the idea is brought to the evaluation phase where it is determined if the idea was successful, and what changes might be made in the future with similar ideas.

Researchers have found some benefits with the use of IDEA boards to promote process improvement on acute care units in hospital systems (Graban \& Schwartz, 2014). However, little published information was identified for application in a health science academic setting. The purpose of this paper is to share the outcomes of a pilot study implemented in an academic setting to examine the usefulness of an IDEA board to move ideas from initial conception to implementation to evaluation.

\section{BACKGROUND}

A College of Nursing Wellness Committee in the Western United States took on the task of implementing and evaluating an IDEA board to help attain wellness goals. Committee members were asked to identify one idea that they would like to see implemented and take charge of that idea through to completion and evaluation. A large cork board was constructed with four vertical sections, each clearly marking phases of the process: (1) "idea" section, (2) "to do" section, (3) "doing" section, and (4) "done" section. In each of these areas, the idea originator was instructed to provide detailed information on what was being done to implement the idea. The board was placed in a visible location in one of the faculty and staff break rooms in the College of Nursing.

\section{METHODS}

The pilot study used a mixed-method design with an eight-question post-intervention survey created to assess usefulness of the IDEA board. The IDEA board was implemented within the Wellness Committee for one fiscal year. During the implementation year, each member of the Wellness Committee who generated a new idea to improve the culture of wellness of the staff and faculty at the College of Nursing used the IDEA board. The 
investigators gathered both quantitative and descriptive data: six of the eight questions asked were Likert-style questions and two of the questions were short-answer format. The pilot study was granted an exempt status by the Institutional Review Board (IRB).

\section{RESULTS}

The responses to the Wellness IDEA board as a tool to enhance generation and completion of ideas were positive. Three of the respondents used the IDEA board to implement a wellness initiative during the 2019-2020 academic year. The participants found the IDEA board useful to hold individuals accountable for ideas and followthrough of ideas discussed during Wellness Committee meetings. Other survey participants identified that the visual representation of an idea provided transparency, organization, and a visual method to track the progress of wellness improvement ideas in the college. For example, one idea generated was a partnership with the University of Utah Peak Fitness Office to offer free blood glucose testing to all College of Nursing faculty and staff. The leader of the event coordinated with Peak Fitness to schedule a date and time for testing, sent emails to all faculty and staff to make them aware of the event, and used wellness committee funds to purchase refreshments for those participating. This individual used the IDEA board to document the steps of the process from the idea itself to the done stage. The event was well attended, and plans were made to continue this offering on an annual basis (Figure 1).

Figure 1. Copy of the Electronic Shared IDEA Board Including Peak Fitness Example
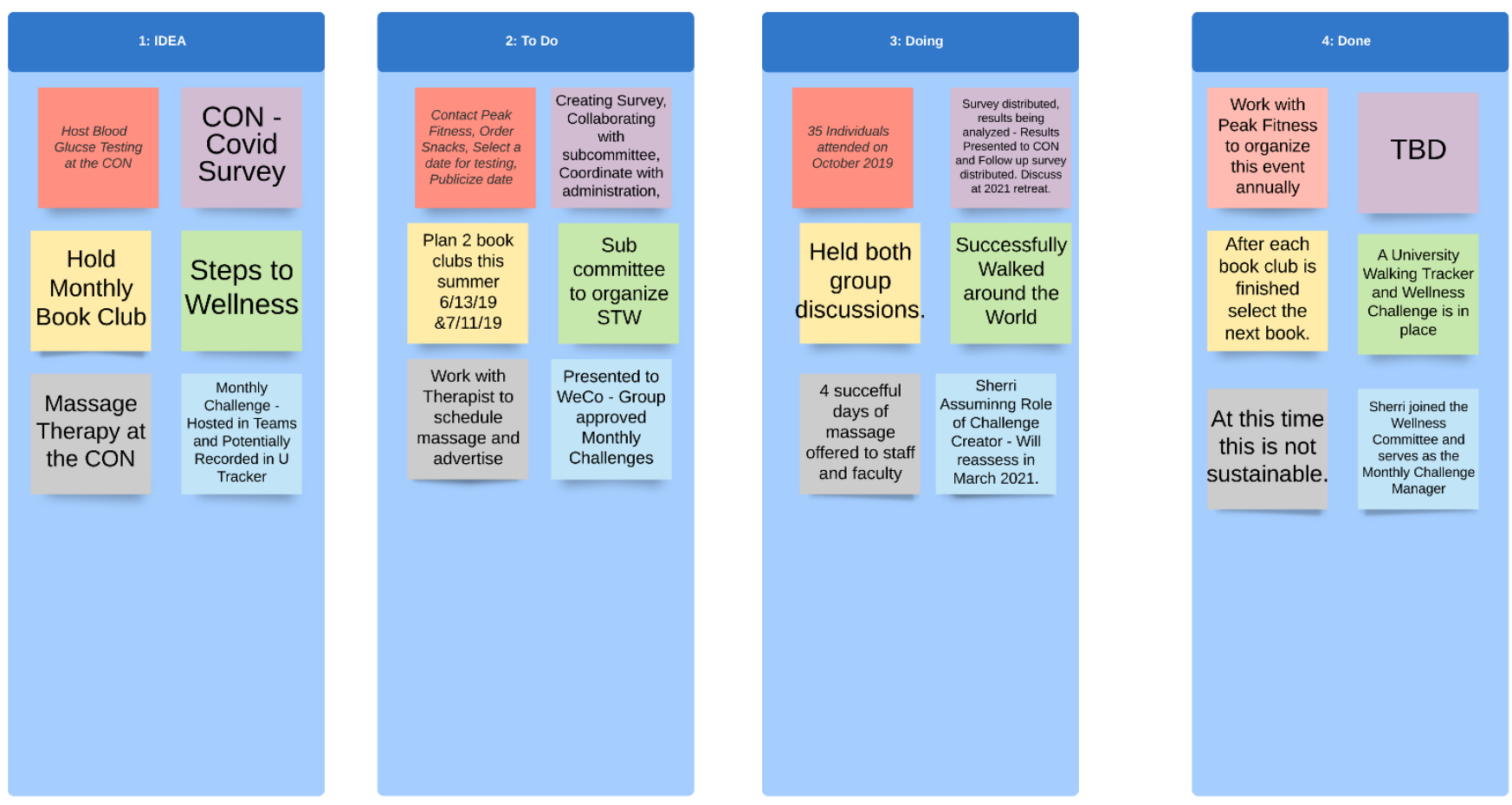
The survey participants also noted opportunities for improvement in the IDEA board initiative. These included that not all committee members could visually see the board at regular intervals, follow-through of ideas could be improved, and learning more about the use of the IDEA board would help all committee members use the board more effectively.

\section{DISCUSSION}

The primary goal of the IDEA board pilot project was to better understand the utility of an IDEA board to improve the implementation and evaluation of ideas for wellness improvement. From the results of this pilot study, the investigators found the IDEA board useful as a tool to generate transparent ideas and move ideas forward. The investigators identified opportunities for growth when using the IDEA board in an academic health science setting. These included reviewing the intended use of the IDEA board within the Wellness Committee once a year and assigning one wellness committee member to facilitate management and organization of the board. This designated person should provide a monthly report and update for the committee and offer intermittent reviews focused on appropriate use of the board. In addition, creating an electronic shared version of the IDEA board would improve access and transparency (Figure 1).

The investigators also suggest that implementation and use of the IDEA board be made available to all staff and faculty at the College of Nursing as this would provide greater opportunity for engagement, leadership, and incorporation of "seeds" of diverse wellness improvement throughout the College.

\section{CONCLUSION}

IDEA boards can be used successfully as part of a systematic process to generate ideas and improve follow-through of those ideas. These visual representations have the potential to support and improve the culture of wellness within a health science academic work setting. 


\section{References}

Amaya, M., Melnyk, B. M., Buffington, B., \& Battista, L. (2017). Workplace wellness champions: Lessons learned and implications for future programming. Building Healthy Academic Communities Journal, 1(1), 143149. https://doi.org/10.18061/bhac.v1i1.5744

Borah, B. J., Egginton, J. S., \& Shah, N. D. (2015). Association of worksite wellness center attendance with weight loss and health care cost savings: Mayo Clinic's experience. Journal of Occupational and Environmental Medicine, 57(3), 229-234. https://doi.org/10.1097/JOM.0000000000000392

Brown, M. C., Harris, J. R., Hammerback, K., Kohn, M. J., Parrish, A. T., Chan, G. K., Ornelas, I. J., Helfrich, C. D., \& Hannon, P. A. (2020). Development of a wellness committee implementation index for workplace health promotion programs in small businesses. American Journal of Health Promotion. 34(6), 614621. https://doi.org/10.1177/0890117120906967

Cheema, A., \& Bagchi, R. (2011). The effect of goal visualization on goal pursuit: Implications for consumers and managers. Journal of Marketing, 75(2), 109-123. https://doi.org/10.1509/jm.75.2.109

Graban, M., \& Swartz, J. E. (2014). The executive guide to healthcare kaizen: Leadership for a continuously learning and improving organization. New York, New York: Productivity Press. https://doi.org/10.1201/b15381

Hill-Mey, P. E., Kumpfer, K. L., Merrill, R. M., Reel, J., Hyatt-Neville, B., \& Richardson, G. E. (2015). Worksite health promotion programs in college settings. Journal of Educational Health

Promotion, 4(12). https:// doi.org/10.4103/2277-9531.154019

Office of Disease Prevention and Health Promotion. (2020, October). Workforce - Healthy People 2030. U.S. Department of Health and Human Services https://health.gov/healthypeople/objectives-and-data/browseobjectives/workforce

Address Author correspondence to:

Jennifer Macali, DNP, MSN, RN, MPH

The University of Utah

jennifer.macali@nurs.utah.edu

\section{Acknowledgments}

We would like to acknowledge our colleagues Dr. Katarina Felsted, Dr. Jennifer Clifton, and Luca Boi for supporting the IDEA board project. 